\title{
AtMNDI is required for homologous pairing during meiosis in
} Arabidopsis

\author{
Aneesh P Panoli ${ }^{1}$, Maruthachalam Ravi ${ }^{1}$, Jose Sebastian ${ }^{1}$, Bindu Nishal ${ }^{1}$, \\ Thamalampudi V Reddy ${ }^{1,2}$, Mohan PA Marimuthu ${ }^{1}$, Veeraputhiran Subbiah ${ }^{1}$, \\ Virupapuram Vijaybhaskar ${ }^{1}$ and Imran Siddiqi*1
}

Address: ${ }^{1}$ Centre for Cellular and Molecular Biology, Uppal Road, Hyderabad - 500007, India and ${ }^{2}$ Present address: Biotechnology Division, Institute of Himalayan Bioresource Technology, Palampur - 176061, Himachal Pradesh, India

Email: Aneesh P Panoli - aneeshpp@ccmb.res.in; Maruthachalam Ravi - mravi@ccmb.res.in; Jose Sebastian - jose@ccmb.res.in; Bindu Nishal - bindu@ccmb.res.in; Thamalampudi V Reddy - tvr_gene_2000@yahoo.com; Mohan PA Marimuthu - prems@ccmb.res.in; Veeraputhiran Subbiah - vsubbu@ccmb.res.in; Virupapuram Vijaybhaskar - vvbr@ccmb.res.in; Imran Siddiqi* - imran@ccmb.res.in

* Corresponding author

Published: 27 July 2006

BMC Molecular Biology 2006, 7:24 doi:10.1186/147|-2199-7-24

This article is available from: http://www.biomedcentral.com/I47/-2199/7/24

(c) 2006 Panoli et al; licensee BioMed Central Ltd.

This is an Open Access article distributed under the terms of the Creative Commons Attribution License (http://creativecommons.org/licenses/by/2.0), which permits unrestricted use, distribution, and reproduction in any medium, provided the original work is properly cited.
Received: 22 May 2006

Accepted: 27 July 2006

\begin{abstract}
Background: Pairing of homologous chromosomes at meiosis is an important requirement for recombination and balanced chromosome segregation among the products of meiotic division. Recombination is initiated by double strand breaks (DSBs) made by Spo I I followed by interaction of DSB sites with a homologous chromosome. This interaction requires the strand exchange proteins Rad5I and Dmcl that bind to single stranded regions created by resection of ends at the site of DSBs and promote interactions with uncut DNA on the homologous partner. Recombination is also considered to be dependent on factors that stabilize interactions between homologous chromosomes. In budding yeast Hop2 and Mndl act as a complex to promote homologous pairing and recombination in conjunction with Rad5I and Dmcl.

Results: We have analyzed the function of the Arabidopsis orthologue of the budding yeast MNDI gene (AtMNDI). Loss of AtMNDI did not affect normal vegetative development but caused fragmentation and missegregation of chromosomes in male and female meiosis, formation of inviable gametes, and sterility. Analysis of the Atmnd I Atspol I-I double mutant indicated that chromosome fragmentation in Atmnd I was suppressed by loss of Atspo I I-I. Fluorescence in situ hybridization (FISH) analysis showed that homologous pairing failed to occur and homologues remained apart throughout meiosis. AtMNDI showed strong expression in meiocytes as revealed by RNA in situs.
\end{abstract}

Conclusion: We conclude that AtMNDI is required for homologous pairing and is likely to play a role in the repair of DNA double strand breaks during meiosis in Arabidopsis, thus showing conservation of function with that of MNDI during meiosis in yeast. 


\section{Background}

The formation of at least one crossover between pairs of homologous chromosomes is necessary for their correct segregation at meiosis I. The stages of interactions between homologous chromosomes that lead to crossover formation have been broadly grouped as: an initial localization of homologous chromosomes within the same region, mediated by interstitial interactions; close pairing and strand exchange at the DNA level as a part of recombination; and synapsis between homologous chromosomes together with completion of recombination [1].

Recombination at the DNA level in yeast and in other organisms is initiated by double strand breaks (DSBs) made by Spo11 $[2,3]$. Interaction between DSBs and a homologous intact chromosome can lead to crossover and noncrossover recombination products which are formed by two different pathways [4]. Processing of DSBs by $5^{\prime}$ end resection yields 3 ' single-stranded ends that asymmetrically invade a homologous chromosome and lead to the formation of a double-Holliday junction intermediate which has been proposed to account for the majority of crossovers $[5,6]$. Interaction between homologous chromosomes at the sites of DSBs is promoted by the action of the RecA-like strand exchange proteins Rad51 and Dmc1 $[7,8]$. Several lines of evidence suggest that Rad51 and Dmc1 have different but overlapping functions $[9,10]$ and interact with distinct sets of proteins in promoting recombination [11-13]. Rad51 acts in mitosis and in meiosis [14] whereas Dmc1 is meiosis specific [15].

MND1 was identified in Saccharomyces cerevisiae using three different screens based on genetic and functional genomic approaches that were directed at identifying genes that played a role in meiotic recombination and/or chromosome segregation [16-18]. The mnd1 mutant shows defects in nuclear division, meiotic recombination, and repair of DSBs. Mnd1 has been shown to act as a complex with Hop2 $[18,19]$ and the Mnd1/Hop2 complex localizes to chromosomes independently of Rad51 and Dmc1 $[18,20]$. Genetic studies have provided evidence that Hop2 and Mnd1 act in the same pathway as Dmc1 and Rad51 [17-21]. Biochemical studies using yeast, human, and mouse orthologues have provided evidence that Mnd1/Hop2 stimulates the strand exchange activity of Dmc1 and that of Rad51 $[19,22,23]$. The interaction of Mnd1 with Hop2 has been shown to promote the interaction of Hop2 with Dmc1 and stimulate the strand exchange activity of Dmc1 [24]. Additional roles for Mnd1/Hop2 that have been proposed are in promoting interhomologue associations at DSBs through interaction with the axial elements or other proteins perhaps by relieving structural constraints $[18,20,25]$ and in the designation of DSBs for noncrossover recombination [26].
Orthologues of MND1 have been identified in protists, fungi, plants, and animals and some of these have been characterized and shown to have closely related functions [27]. In yeast an mnd1 disruption has been reported to cause defects only in meiosis and does not result in sensitivity to radiation induced DNA damage [17]. However, an Arabidopsis mutant, Atmnd1- $\Delta 1$ has been recently shown to be sensitive to gamma radiation indicative of a role in mitotic repair, and also to undergo chromosome fragmentation during meiosis [28]. Here we have used the same mutant allele to analyze the role of the AtMND1 gene in meiosis. We show that AtMND1 is required for homologous pairing, an early step in the recombination process and that chromosome fragmentation in the Atmnd1 mutant is likely to be due to defective repair of meiotic DSBs. We also show that consistent with its role in meiosis, AtMND1 is strongly expressed in meiocytes.

\section{Results \\ AtMNDI shows increased expression in reproductive tissues}

The Arabidopsis genome contains a single orthologue of MND1 (AtMND1) corresponding to the annotated gene ID No. At4g29170 and supported by a cDNA (Accession No. AA063855). The encoded protein shows $26 \%$ identity ( $47 \%$ similarity) to Mnd 1 and is 230 aa in length which is close to that of Mnd1 (219 aa). Expression of AtMND1 was compared between rosette leaves and inflorescence using real time PCR (Fig. 1B). The results indicated a 9fold higher expression of AtMND1 in reproductive tissues over leaves consistent with a possible role in reproductive development.

\section{Mutation of AtMND I causes male and female sterility due to production of defective gametes}

To examine the function of the AtMND1 gene we obtained bulked $\mathrm{T} 4$ seeds of an insertion line SALK_110052 [29] carrying a T-DNA insertion in AtMND1 and identified 2 plants that were homozygous for the insertion. Both plants were found to be sterile (Fig. 2) whereas $14 / 14$ plants that were not homozygous for the insertion were fertile. No defects in vegetative development were observed. The progeny of a single plant that was heterozygous for the insertion segregated 84:23 fertile:sterile consistent with a single gene recessive trait $(0.5$ $>\mathrm{p}>0.25$ for a single gene model; $0.001>\mathrm{p}$ for a two gene model). 31 plants at random were genotyped with respect to the presence of the insertion and all 4 that were found to be homozygous for the insertion were also sterile indicating that the phenotype was closely linked to the insertion ( $0.001>\mathrm{p}$ for an unlinked gene model). The mutant showed a greater than 100-fold reduction in AtMND1 expression suggesting that AtMND1 function is severely reduced and is probably null (data not shown). To determine whether sterility was caused by mutation of 
A

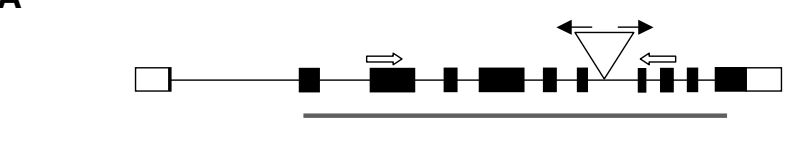

B

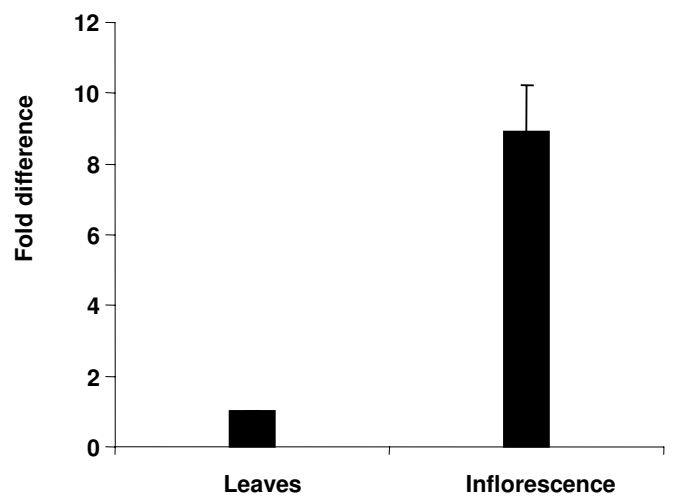

\section{Figure I}

Gene structure and expression of AtMNDI. (A) Line diagram showing the site of T-DNA insertion in the AtMND I gene. Exons and the UTR's are indicated as black boxes and clear boxes respectively. Inverted triangle in the seventh intron represents the site of T-DNA insertion. The black and white arrows represent the LBI and the gene-specific primers used to genotype plants. The black bar below the gene represents the Mnd I domain in the protein. (B) Real Time RT-PCR analysis of relative expression of AtMNDI in somatic and reproductive tissues. The constitutive GAPC gene was used as the normalization control.

AtMND1, a $3.9 \mathrm{~kb}$ genomic fragment comprising the AtMND1 gene and its promoter region was cloned into a plant binary vector pCAMBIA1300 [30] and transformed into Arabidopsis plants that were heterozygous for the Atmnd1 insertion allele, using in-planta transformation. 4 T1 transformant plants that were homozygous for the Atmnd1 insertion allele were identified out of 24 screened and all 4 were fertile, whereas among untransformed plants in a segregating population, 12 were identified to be homozygous for the Atmnd1 insertion allele and all were sterile (Fig. 2B) which demonstrates that the sterile phenotype is caused by mutation of AtMND1.

Reciprocal crosses were carried out between wild type and mutant to identify the developmental defects underlying sterility, and the results in Table 1 indicate that the mutant shows both male and female sterility. Observation of anthers showed that the pollen grains in the mutant were shrunken (Fig. 2F,G) and inviable (Fig. 2K,O) as determined by Alexander staining [31]. Also the anther lobes remained below the level of the stigma as a result of
Table I: Reciprocal crosses between wild type and Atmnd I mutant.

\begin{tabular}{lcc}
\hline Female parent & Male parent & No. of seeds per silique \\
\hline Atmndl & Wild type & $1+/-1$ \\
Wild type & Atmndl & 0 \\
Wild type & Wild type & $58+/-5$ \\
\hline
\end{tabular}

Data shown are from a minimum of ten crosses.

reduced elongation of the anther filament. Likewise, examination of cleared ovules showed that in the mutant, postmeiotic development of the female gametophyte was arrested at the functional megaspore stage followed by degeneration of the functional megaspore (Fig. $2 \mathrm{H}-\mathrm{J}, \mathrm{L}-\mathrm{N}$; Table 2). About $0.6 \%$ of the developed ovules contained a mature embryo sac, which is consistent with the small number of seeds produced in the mutant. These results indicated that the mutant is male and female sterile due to both pollen and embryo sac formation being defective.

\section{AtMNDI is strongly expressed at meiosis}

To obtain more detailed information on the expression pattern of AtMND1 in relation to the mutant phenotype we examined expression in inflorescence tissue sections by RNA in-situ hybridization using antisense RNA complementary to AtMND1 cDNA (Fig. 3). A basal level of expression was observed throughout reproductive tissues. In addition strong expression of AtMND1 was found within anther lobes at meiotic stages (Fig. 3A-E). The earliest increase in expression was detected in sporogenous cells at anther stage 4 [32]. Strong expression was observed in stage 5 anthers within microspore mother cells and also the tapetum. A high level of expression continued to be observed within meiotic cells during anther stage 6 and declined after meiosis. An increase in expression of AtMND1 was also detected within the megaspore mother cell in ovules although not as strongly as observed in microsporocytes (Fig. 3G).

\section{AtMNDI is required for homologous pairing}

The expression pattern of AtMND1 and the phenotype of the AtMND1 mutant are together suggestive of a defect in meiosis. We therefore compared meiotic prophase stages from the mutant and wild type using spread preparations of meiotic chromosomes following the method of Ross et al., 1997 [33]. The initial stages of meiotic prophase corresponding to early leptotene were seen to occur in the Atmnd1 mutant and thread-like chromosomes were apparent (Fig. 4). Association of the nucleolar heterochromatin present on chromosomes 2 and 4 as well as the synizetic knot, which is formed during late leptotene concomitant with pairing and the start of synapsis [34] could also be observed (Fig. 4A,F). However, abnormalities could be detected starting at the zygotene stage, both 

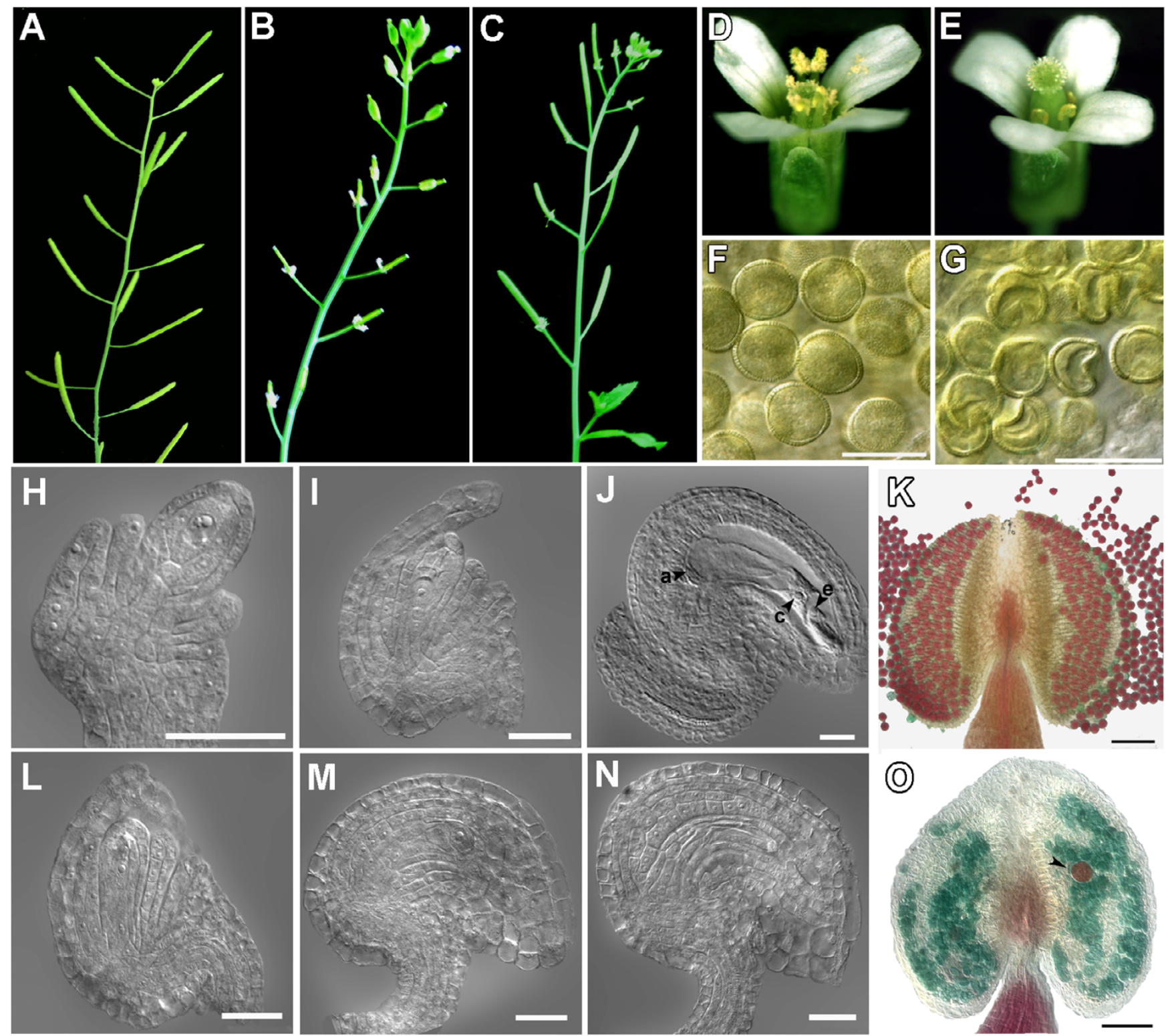

\section{Figure 2}

The Atmnd I mutant shows sterility. (A,D,F,H,I,J,K) Wild-type, (B,C,E,G,L,M,N,O) Atmnd I. (A) Wild-type Arabidopsis with elongated siliques. (B) Sterile Atmnd I plant with non-elongated siliques. (C) Mutant plant transformed with a wild-type AtMND I gene displaying restoration of fertility. (D) Wild-type flower. (E) Mutant flower showing under-developed stamen and stigma devoid of pollen grains. (F) Cleared anther containing round and uniformly sized pollen grains. (G) Mutant anther containing shriveled pollen grains. (H) Stage 2-4 ovule displaying the megaspore mother cell (MMC). (I,L) Stage 3-I ovule showing the functional megaspore (J) Cleared wild type mature embryo sac; a, antipodals; c, central cell; e, egg cell. $(\mathrm{K}, \mathrm{O})$ Alexander staining for pollen viability; arrowhead indicates a rare purple viable pollen grain in the mutant. (M) Mature ovule with female gametophyte arrested at the uninucleate stage. (N) Mature ovule containing degenerating material instead of an embryo sac. Scale bars: K, O, $50 \mu \mathrm{m} ; \mathrm{H}-\mathrm{J}, \mathrm{L}-\mathrm{N}, 20 \mu \mathrm{m}$. Ovule stages are according to [54].

with respect to the appearance of the chromosomes and the organization of pericentromeric heterochromatin. Chromosomes in the mutant appeared less compact when compared to wild type and pericentromeric heterochromatin regions were more extended and unpaired than at the corresponding stage in wild type (Fig. 4B,G). During the course of zygotene, the differences became more pronounced, and synapsis was defective. The thickening of chromosomes along segments of their length representing synapsed regions, that characteristically appears during 
Table 2: Female gametophytic defects in the AtmndI mutant.

\begin{tabular}{|c|c|c|c|c|c|c|c|c|c|c|c|c|}
\hline \multirow[t]{2}{*}{ Ovule Stages } & \multicolumn{2}{|c|}{ In } & \multicolumn{2}{|c|}{$2 n$} & \multicolumn{2}{|c|}{$4 n$} & \multicolumn{2}{|c|}{$8 n$} & \multicolumn{2}{|c|}{ MES } & \multicolumn{2}{|c|}{ Degen } \\
\hline & $\mathrm{m}$ & + & $\mathrm{m}$ & + & $\mathrm{m}$ & + & $\mathrm{m}$ & + & $\mathrm{m}$ & + & $\mathrm{m}$ & + \\
\hline $3-1$ & 31 & 100 & ND & ND & ND & ND & ND & ND & ND & ND & 69 & ND \\
\hline $3-2$ & 25 & 60 & 9 & 40 & ND & ND & ND & ND & ND & ND & 66 & ND \\
\hline $3-4$ & 39 & 2 & 4 & 40 & 7 & 52 & ND & 5 & ND & ND & 50 & 0.8 \\
\hline $3-6$ & 32 & ND & 6 & 2 & 0.4 & 7 & 0.2 & 7 & 0.6 & 83 & 60 & 1.2 \\
\hline
\end{tabular}

Stages of female gametophyte development relative to ovule stages in the AtmndI mutant and wild type. A total of 759 and 637 ovules were scored for the Atmnd I mutant and wild-type respectively. Megagametogenesis defects are evident from stage 3-I in case of the mutant, which leads to embryo sac arrest and eventually its degeneration. Ovule stages are according to [54]: 3-I, 3-2, and 3-4 are postmeiotic stages of the sporophyte with respect to elongation of the integuments where the wild type gametophyte would normally reach the In, $2 \mathrm{n}$, and $4 \mathrm{n}$ stages; $3-6$ corresponds to a mature ovule prior to fertilization. MES, Mature embryo sac; Degen, Degenerated embryo sac; $M$, mutant; +, wild type; ND, Not detected.

zygotene and is complete by pachytene, did not take place in the mutant (Fig. 4C,H). At diplotene the chromosomes appeared as a diffuse and fragmented mass with 10-12 separate spots of condensed pericentromeric heterochromatin (Fig. 4D,I). At diakinesis, separated chromosomes and fragments could be clearly distinguished (Fig. 4E,J). The sorting of these fragments at anaphase I and II was irregular and bridges could be observed (Fig. 4K-N,P-S). Following meiosis polyads that contained a variable number of fragmented chromosomes were formed (Fig. $4 \mathrm{O}, \mathrm{T})$. These gave rise to defective spores that did not form viable pollen. Female meiosis in the mutant was also defective and chromosome fragmentation was observed (Fig. 4U-W). These data suggested the possibility that the mutant is defective in homologous pairing and synapsis and the accumulation of fragments may arise from defects in repair of DSBs.

To examine homologous pairing we carried out FISH experiments (Fig. 5) using a telomere repeat based oligonucleotide probe that hybridizes strongly to the centromere of chromosome 1 but not to centromeres of the remaining chromosomes [35]. In wild type, two well separated signals were observed at leptotene indicating that chromosomes were unpaired (Fig. 5A). A single signal was observed at late zygotene (46/46 nuclei) and pachytene (23/23 nuclei) indicative of pairing and synapsis having taken place (Fig. 5C,D). At diplotene, twin signals close to each other ( $6 / 6$ nuclei) were seen indicative of centromere regions having desynapsed (Fig. 5E). These twin signals again merged and at metaphase I only a single signal was seen (data not shown). The Atmnd1 mutant showed two widely separated signals starting from leptotene and throughout all subsequent stages (58/61 nuclei for zygotene and 42/43 for pachytene) indicating that homologous pairing as well as synapsis was defective (Fig. 5F-J).

\section{Chromosome fragmentation in Atmnd I is suppressed by a mutation in AtSPO I I-I}

The chromosome fragmentation phenotype together with the absence of homologous pairing suggested that the Atmnd1 mutant was defective in recombination possibly due to defects in the repair of meiotic DSBs. AtSPO11-1 is one of three SPO11 homologues in Arabidopsis and is specifically required for recombination and synapsis during meiosis [36,37]. To test whether fragmentation was dependent upon Atspo11-1, a plant that was heterozygous for Atmnd1 was crossed to a SALK insertion line (SALK_146172) that was heterozygous for a T-DNA insertion in the seventh intron of Atspo11-1 [29]. F1 plants that carried both insertions were identified in the F1 and homozygous Atmnd1 Atspo11-1 double mutants were obtained in the F2. Analysis of male meiotic chromosome spreads of the double mutant and comparison to the Atspo11-1 single mutant indicated that the chromosome fragmentation phenotype of Atmnd1 was suppressed by Atspo11-1 (Fig. 6). Chromosomes in the double mutant did not undergo fragmentation after diplotene (Fig. 6B,C) and remained as intact univalents that segregated randomly at the first meiotic division (Fig. 6C,D,H,I). The double mutant phenotype resembled that of the Atspo111 mutant. Atspo11-1 is therefore epistatic to Atmnd1.

\section{Discussion}

Pairing and recombination between homologous chromosomes at meiosis relies on search for homology using resected ends that are created at the sites of DSBs. This search is mediated by the action of RecA-like strand exchange proteins Rad51 and Dmc1 which bind to single stranded DNA and promote the formation of joint molecules $[7,8]$. The strand exchange activity of Dmc1 and Rad51 is stimulated by Hop 2 and Mnd 1 which cooperate together as a complex $[18,19]$. Both Hop2 and Mnd1 are required in yeast for homologous pairing and meiotic DSB repair [16-18,20]. We have shown in this study that the Arabidopsis orthologue of MND1, AtMND1 is required for homologous pairing during meiosis in Arabidopsis 

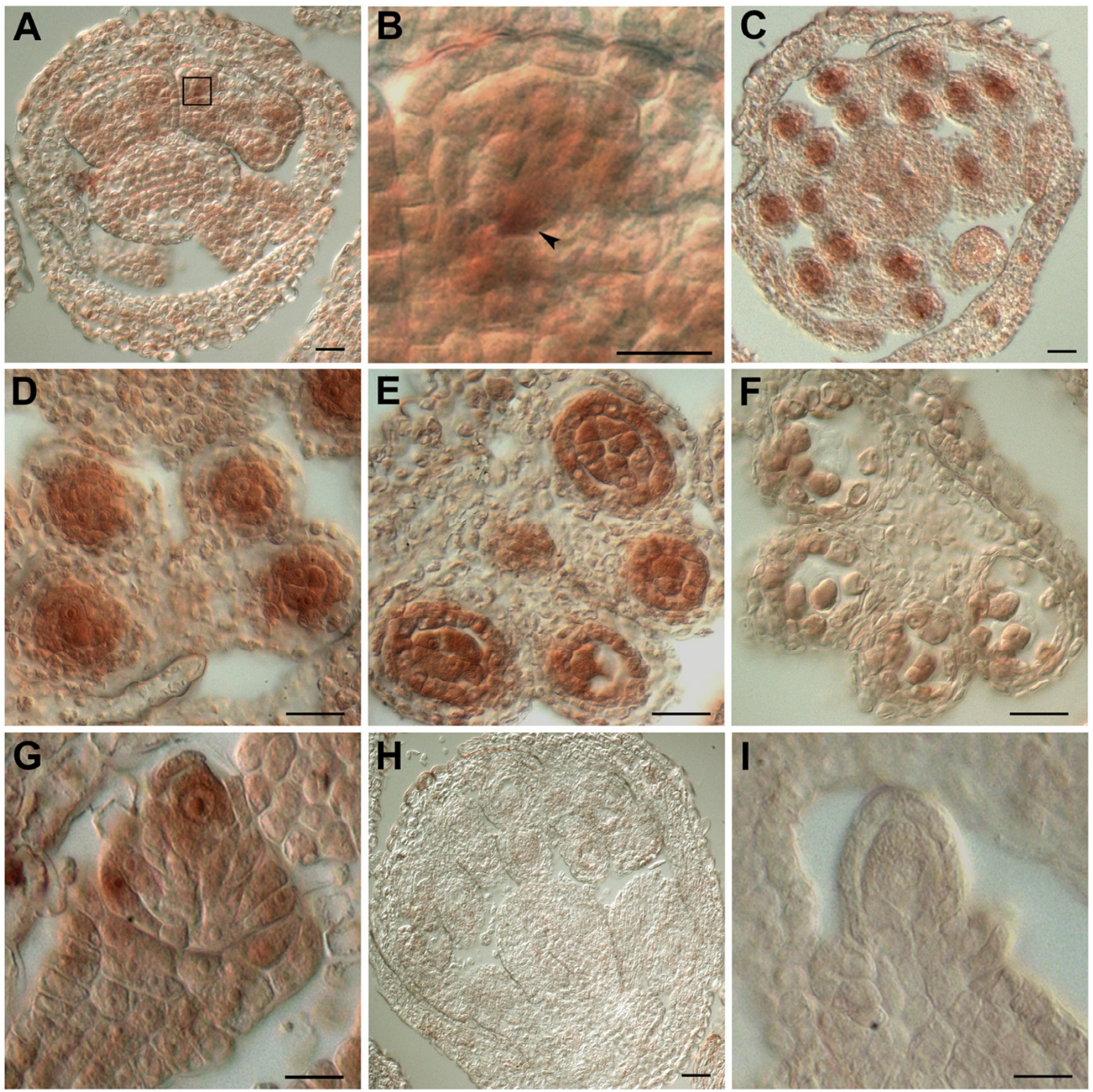

\section{Figure 3}

Expression of AtMNDI in male and female meiocytes. RNA in-situ hybridization of AtMND I anti-sense RNA to flower buds. (A-F,H) Transverse sections of anthers. (G,I) Transverse sections of pistils. (A) Increased levels of expression first detected in stage 4 anther locules. (B) Magnification of inset in (A) showing increased expression in sporogenous cells (arrowhead). (C,D) Stage 5 anthers showing strong expression in pollen mother cells and tapetum. (E) Stage 6 anther containing meiotic cells. (F) Expression declines at the tetrad stage. $(G)$ Increased expression in megaspore mother cell. $(H, I)$ Sense controls. Scale bar: $25 \mu \mathrm{m}$. 

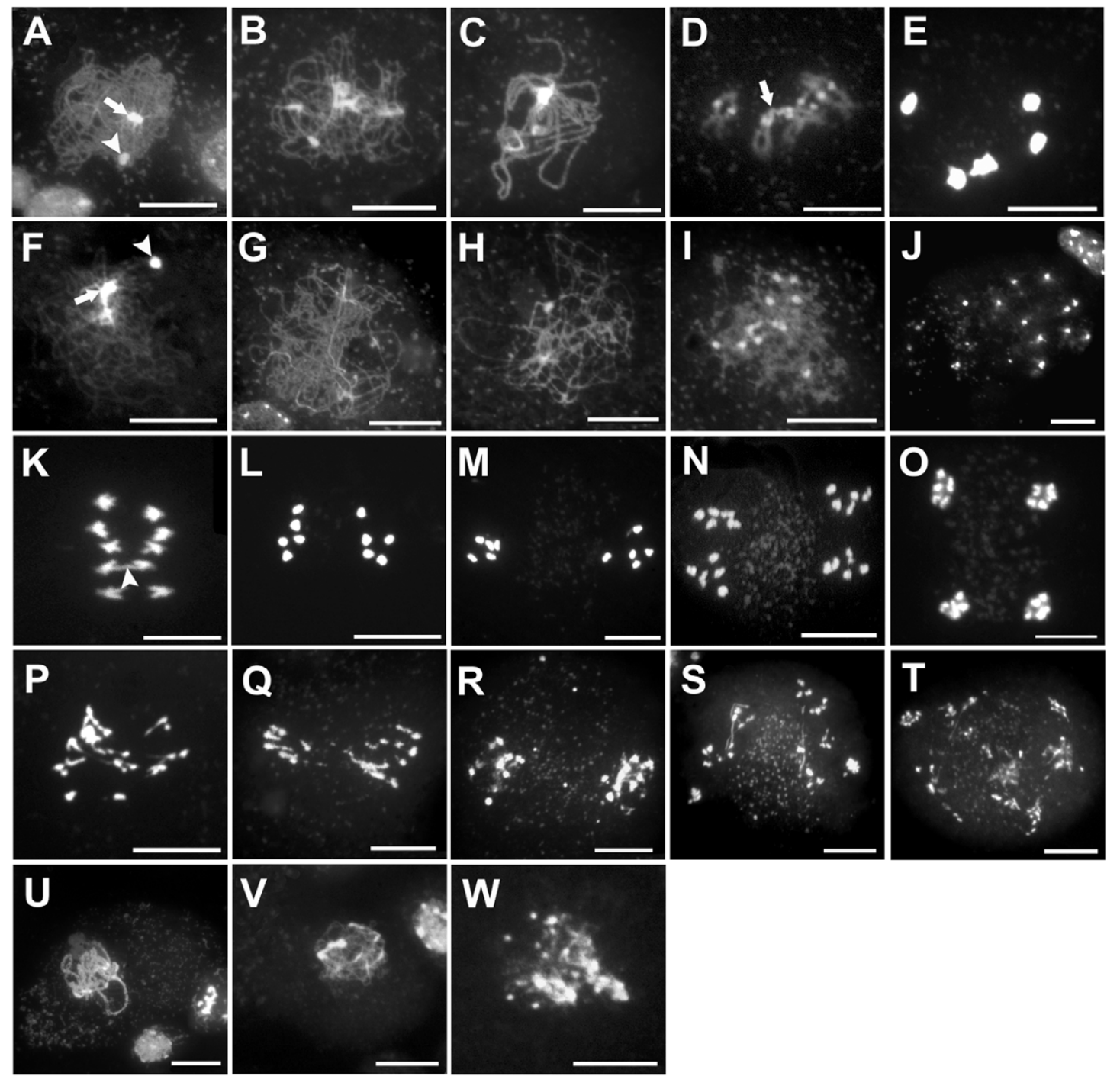

Figure 4

Meiotic defects in the AtmndI mutant. (A-E, K-O, U) Wild type, (F-J, P-T, V and W) AtmndI. (A-T) Male meiosis, (U-W) female meiosis. (A,F) Unsynapsed elongated strands of chromosomes at late leptotene radiating from densely stained synizetic knot (arrow). The NOR is indicated by arrowhead. (B) Zygotene stage with partially synapsed chromosomes. (C) Synapsis is complete at pachytene and chromosomes have a shorter and thicker appearance. (D) Late diplotene stage, where bivalents have undergone partial decondensation of the arms but not at centromeric regions. Arrow indicates the NOR. (E) Diakinesis with brightly stained bivalents. (G) Unsynapsed chromosomes at stage corresponding to zygotene with the chromosomes remaining as univalents. $(\mathrm{H})$ Pachytene equivalent stage showing irregular and unsynapsed univalent chromosomes. (I) Diplotene stage with patchy and fragmented chromosomes. $(\mathrm{J})$ Occurrence of more than ten brightly stained spots indicates univalent chromosomes and their fragmented form at diakinesis. (K) Five separating univalents at early anaphase I. Residual chiasma can be seen in one of the separating bivalents (arrowhead). (L) Late anaphase I. (M) Metaphase II. (N) Anaphase II. (O) Telophase II. (P) Anaphase I with numerous chromosome fragments migrating to either pole. (Q) Abnormal segregation of fragmented chromosomes at late anaphase I. (R) Fragmented chromosomes aligned at the metaphase II plate. (S) Anaphase II, showing scattered chromosome fragments and bridges probably representing sister chromatid cross over. (T) Telophase II with polyads. $(U)$ Female meiocytes at pachytene with fully synapsed chromosomes. $(V)$ Corresponding stage as in $U$ with chromosomes appearing fuzzy, remaining as univalents. (W) Female meiocyte at late prophase I showing extensive chromosome fragmentation. Scale Bars: $10 \mu \mathrm{m}$. 

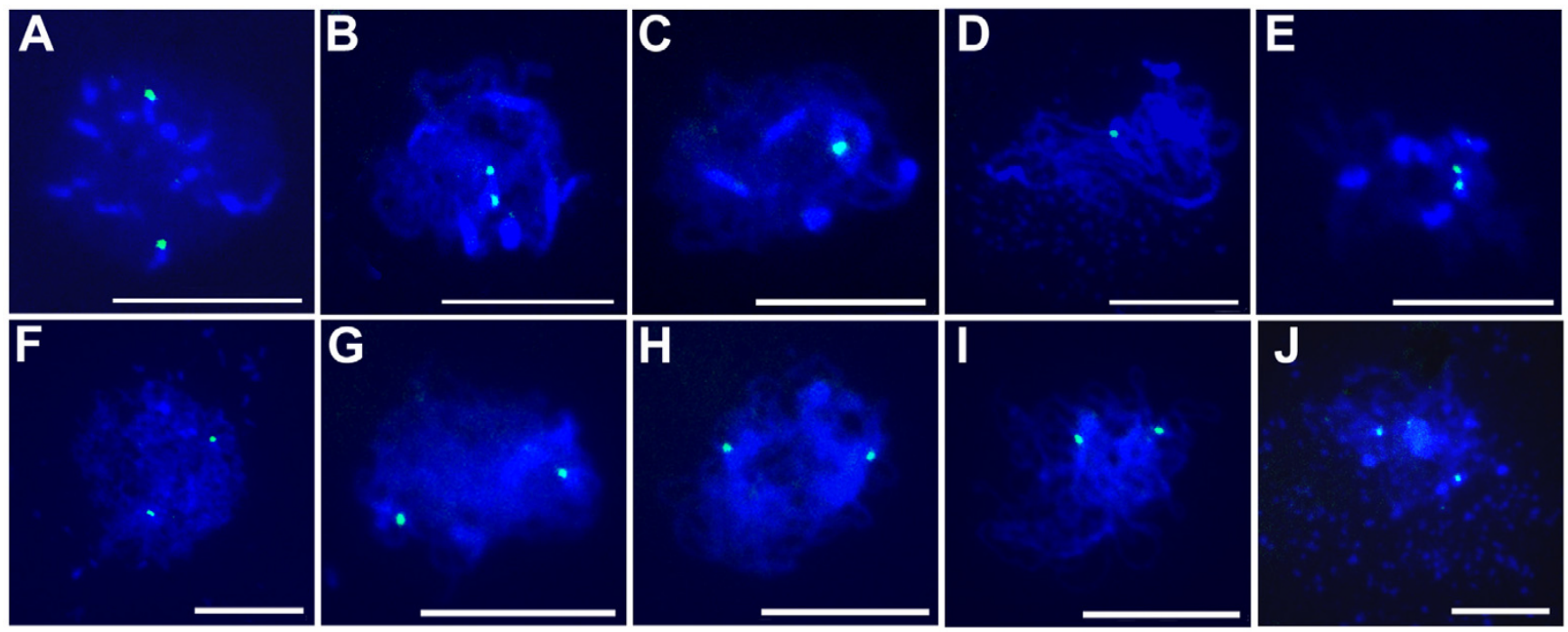

Figure 5

FISH analysis of homologous pairing in wild-type and AtmndI plants. (A-E) Wild type, (F-J) Atmnd I. (A,F) Early leptotene with two green signals indicating that homologous chromosomes are unpaired. $(B, G)$ Two signals observed at leptotenezygotene transition. (C) Late zygotene stage with only one signal indicating that the chromosomes have synapsed. (D) Pachytene stage with one signal. (E) Desynapsis occurring at centromeres during diplotene as evident by two closely appearing signals. $(\mathrm{H})$ Late zygotene stage, with two signals placed far apart indicating unpaired state of homologous chromosomes. (I) Pachytene equivalent stage, where two signals are evident (J) Diplotene with two widely separated signals. Scale Bars: I0 $\mu$ m.

where it is likely to play a role in the repair of meiotic DSBs. AtMND1 also shows strong expression in meiocytes.

The early defects in the Atmnd1 mutant with respect to overall appearance of chromosomes during meiosis were a lack of thickening during zygotene and absence of subsequent synapsis at pachytene. Fragmentation of chromosomes became apparent at diplotene and isolated univalents and fragments were first visible at diakinesis. FISH analysis using a centromere 1 specific probe indicated that homologous pairing did not take place in the mutant during zygotene and homologous chromosomes remained apart throughout meiotic prophase and meiosis I.

The meiotic phenotype of Atmnd1 is similar to that caused by a mutation in AHP2 which encodes the Arabidopsis orthologue of HOP2 [38]. In both cases there is chromosome fragmentation and a defect in homologous pairing. The failure to synapse and the appearance of fragmented chromosomes late in meiotic prophase I is a feature of several Arabidopsis mutants that are implicated in processing and repair of DSBs $[39,40]$. The observation that Atspo11-1 suppressed the chromosome fragmentation phenotype of Atmnd1 supports the interpretation that Atmnd1 is also defective in meiotic DSB repair. A major difference between the meiotic phenotype of yeast $m n d 1$ and that for Atmnd1 in Arabidopsis is the absence of meiotic arrest in Arabidopsis whereas mnd1 shows prophase arrest which is alleviated by a mutation in MEC1, a major regulator of DNA damage induced checkpoints [25]. A lack of arrest is also seen in the case of $a h p 2$ whereas hop2 shows prophase arrest [20]. The failure to arrest in the case of Arabidopsis is likely to be due to the absence or leakiness of meiotic DNA damage checkpoints and has also been observed for other Arabidopsis meiotic mutants for which the yeast counterparts show prophase arrest [41].

The yeast MND1 gene is expressed and functions only in meiosis and is not considered to play a role in mitotic DNA repair [17]. The AtMND1 gene is dispensable for somatic development, however the Atmnd1 mutant is defective in mitotic DNA repair and AtMND1 is induced in response to gamma irradiation [28] pointing to an evolutionary difference between yeast and plants with respect to the role of MND1. In plants the major pathway for repair of DSBs in somatic cells is non-homologous end joining (NHEJ) whereas in yeast the homologous recombination pathway predominates, which may explain the requirement for Hop2/Mnd1 in promoting efficient repair of DSBs and the maintenance of genome integrity in somatic cells [42]. Orthologues of MND1 and HOP2 are not present in C. elegans and Drosophila melanogaster both of which do not require DSBs for homologous synapsis at meiosis [43]. 

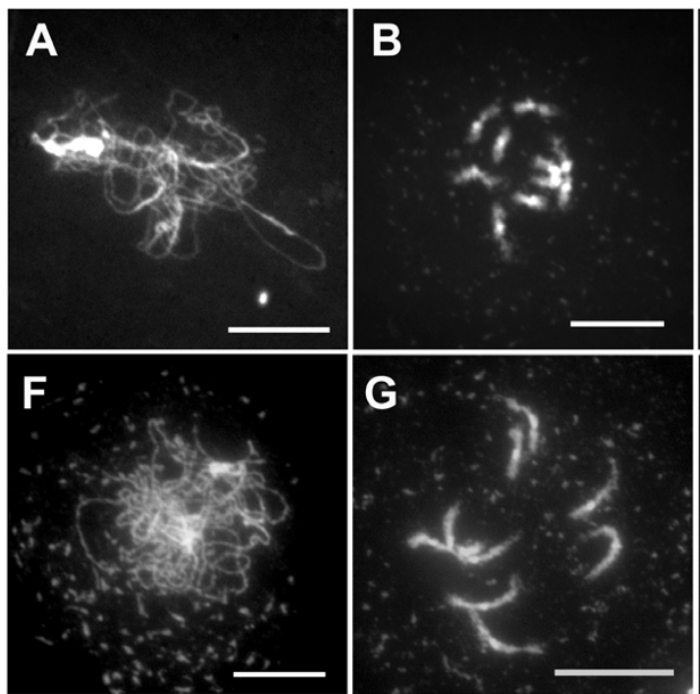
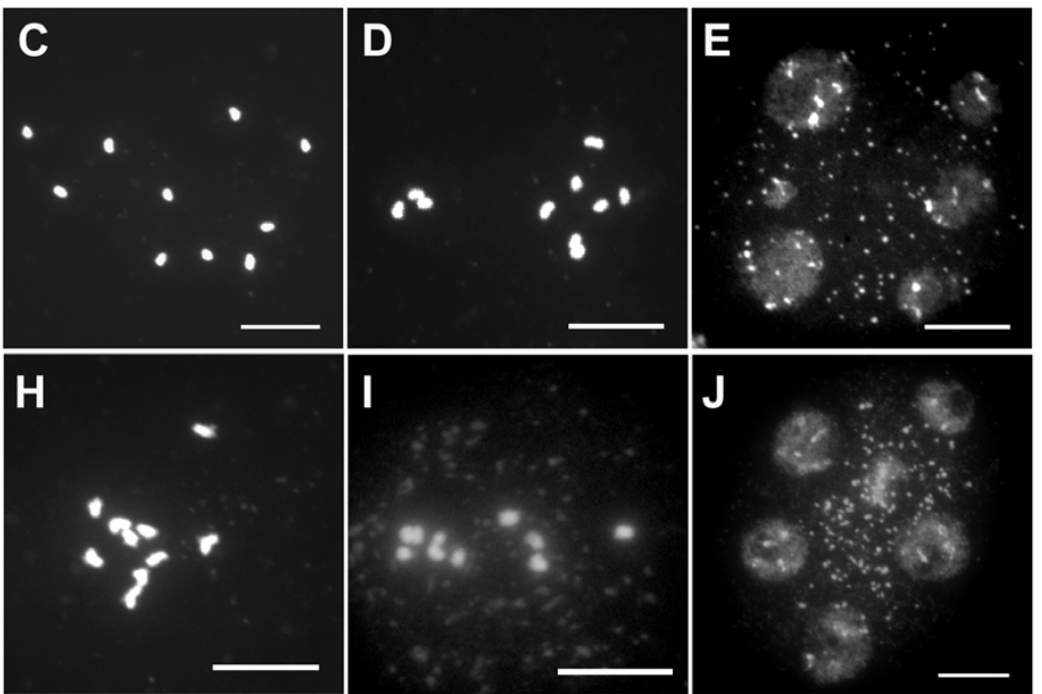

Figure 6

Suppression of chromosome fragmentation in Atmnd I by Atspo I I-I. (A-E) Atspo / I-I Atmnd I double mutant. (F-J) Atspo I I-I single mutant. (A,F) Pachytene equivalent stage with unpaired chromosomes. (B,G) Diplotene stage showing ten condensed univalents; four nucleolus organizing chromosomes are attached together at the NOR. (C,H) Diakinesis with ten brightly stained univalent chromosomes. (D,I) Anaphase I showing 7:3 and 6:4 unequal segregation of chromosomes respectively. (E,J) Polyad. Scale Bar: $10 \mu \mathrm{m}$.

In addition to being strongly induced in meiocytes at the time of meiosis we found that AtMND1 is also expressed in the tapetum at the same time. We have earlier noticed this to also be the case for the DUET gene which has a male meiosis specific phenotype [44]. It is possible that the tapetal expression at the same time as in meiocytes may reflect an overlap in the expression profile between tapetal cells and microspore mother cells which form adjacent layers and are both descended from the archesporial cell. Indeed the secondary parietal cells that are the precursors of the tapetum appear to retain the developmental potential to form meiocytes as revealed by mutations in EXS/EMS1 [45,46] and TPD1 [47] where microsporocytes are formed in place of tapetal cells. We also note that the onset of increased expression of AtMND1 appears to be at anther stage 4 in a region occupied by sporogenous cells that are the precursors of male meiocytes. This stage is prior to the formation of meiocytes and initiation of recombination. These observations would suggest that the regulatory mechanisms responsible for increased expression of AtMND1 in reproductive tissues may be distinct from those for DNA damage inducible expression [28].

\section{Conclusion}

In summary we have shown that AtMND1 is required for homologous pairing and repair of DSBs during meiosis in
Arabidopsis. Loss of AtMND1 does not affect normal vegetative development but causes male and female sterility due to fragmentation and defective segregation of chromosomes in meiosis.

\section{Methods \\ Plant material and growth conditions}

All the plants described in this study were Arabidopsis ecotype Col-0. The T-DNA insertion lines SALK_110052 and SALK_146172 used in this study were obtained from the Arabidopsis Biological Resources Centre, Ohio State University. Plants were grown as described previously [48].

\section{Characterization of the T-DNA Lines}

Genomic DNA was extracted from the SALK T-DNA insertion lines using the method of Dellaporta et al.,1983 [49]. Presence of the T-DNA insert in Atmnd1 was confirmed by PCR using a left border outwardly directed primer (LB1) in combination with a gene-specific primer (AtMND1F1) flanking the site of insertion. Based on our analysis, there are at least two tandemly placed T-DNA inserts placed next to each other such that the orientation in the genome is LB-RB-LB. Junction fragments on either ends of T-DNA were amplified using primer combinations AtMND1F1 and LB1 and AtMND1R1 and LB2. Sequencing of the AtMND1R1-LB2 product revealed the presence of a $86 \mathrm{bp}$ deletion within intron 7. Primers AtMND1F1 and 
AtMND1R1 were utilized to amplify the wild type allele. For the Atspo11-1 line the presence of the T-DNA insert was confirmed using the primer TSPO11R in combination with LB1 and wild type copy using TSPO $11 \mathrm{~F}$ in combination with TSPO11R. Homozygous insertion lines showed a phenotype that was the same as that of Atspo11-1-1 [36].

\section{Complementation analysis}

A full-length genomic clone spanning 3891 bp (AGI coordinates 14382003-14385894) was amplified using primers MndF1 and MndR1 that incorporates restriction sites, Bam $\mathrm{H} 1$ at $5^{\prime}$ and EcoR1 at $3^{\prime}$ end respectively. The amplification was done using TripleMaster PCR system (Eppendorf) as per the manufacturer's instructions. The resulting $3.89 \mathrm{~kb}$ fragment was cloned into the pGEM-T vector (Promega) followed by sequencing of the fragment. Restriction digestion with enzymes BamH1 and EcoR1 was performed to release the fragment, which was sub-cloned into the binary vector pCAMBIA1300. The fragment was mobilized into Agrobacterium strain AGL1 by tri-parental mating. The in planta transformation was carried out on heterozygous Atmnd1 plants by vacuum infiltration as reported earlier [50]. The transformants were selected on medium comprising of $1 \%$ bacto agar, $1 \%$ sucrose, $1 \mathrm{mM}$ $\mathrm{KNO} 3$ and $50 \mu \mathrm{g} / \mathrm{ml}$ of hygromycin $\mathrm{B}$ and genotyped by PCR using Atmnd_out_FG_Rev1 and Atmnd_out_FG_For1 primers.

\section{Expression analysis by Real Time RT-PCR}

Total RNA was isolated using Trizol (Sigma) as per the manufacturers protocol. cDNA was synthesized from 5-7 $\mu \mathrm{g}$ of RNA using the Superscript first strand synthesis system (Invitrogen) with Oligo dT primers. Real Time PCR reactions were done in a $10 \mu \mathrm{l}$ volume comprising of primer, cDNA template and $1 \times$ SYBER Green PCR master mix (Applied Biosystems). GAPC was used as the internal normalization control. PCR was performed on the ABI Prism 7900 HT Sequence Detection System (Applied Biosystems) in a 384 well reaction plate according to the manufacturer's recommendations. Primers were MNDRTF1 and MNDRTR1 for AtMND1 and GAPRTF1 and GAPRTR2 for GAPC. Cycling parameters consisted of 2 minutes incubation at $50^{\circ} \mathrm{C}, 10$ minutes at $95^{\circ} \mathrm{C}$ and 40 cycles of $95^{\circ} \mathrm{C}$ for 15 seconds, $57^{\circ} \mathrm{C}$ for 30 seconds and $67^{\circ} \mathrm{C}$ for 30 seconds. Each PCR reaction was performed in triplicate and the experiment were repeated twice. Specificity of the amplifications was verified at the end of each PCR run using ABI prism dissociation curve analysis software. Results from the ABI Prism 7900 HT Sequence Detection System were analyzed further using Microsoft Excel. Quantification of mRNA was calculated from threshold points ( $\mathrm{Ct}$ values) located in the log-linear range of real time PCR amplification plots.

\section{RNA In situ Hybridizations}

In situ hybridizations were carried out as described earlier [48]. Anti-sense RNA specific to the AtMND1 gene was used as probe along with sense control. We used the fulllength AtMND1 cDNA amplified from the cDNA clone using Nco1F and EcoR1R primers and subcloned into pGEM-T vector for strand specific probe synthesis. Floral stages are according to [51].

\section{Microscopy}

Developmental analysis of whole mount anthers and ovules was done after fixing and clearing the inflorescence in methyl benzoate as described previously [46]. The slides were observed on a Zeiss Axioplan 2 Imaging microscope under DIC optics using a $40 \times$ oil immersion objective. Pollen viability was examined using the method of Alexander staining [31]. Meiotic chromosome spreads were prepared, analyzed, and staged based on chromosomal morphology and with respect to the stage of the surrounding tapetal cells, according to Ross et al., 1996 [33] with minor modifications as described in [52]. Chromosomes were stained with DAPI $(1 \mu \mathrm{g} / \mathrm{ml})$ and observed on a Zeiss Axioplan 2 Imaging microscope using a $365 \mathrm{~nm}$ excitation and $420 \mathrm{~nm}$ long pass emission filter and a $100 \times$ oil objective. Images were captured on an Axioplan CCD camera using Axiovision (version 3.2) and processed using Adobe Photoshop 6.0.

\section{Fluorescence In situ Hybridization (FISH)}

Meiotic spreads were carried out as described above and FISH analysis was done according to [53] with incorporation of minor modifications. The hybridization mix was prepared with 5' FITC labeled probe FITC-(CCCTAAA) 6 [35] at a concentration of $5 \mu \mathrm{g} / \mathrm{ml}$ in $50 \%$ deionised formamide, $2 \times$ SSC and 10\% dextran sulphate. The hybridization mix was denatured on a hot block for 3 minutes at $100^{\circ} \mathrm{C}$ and immediately cooled on ice. The slides were denatured separately with $100 \mu$ l denaturation mix comprising of $70 \%$ deionised formamide, $2 \times$ SSC and $50 \mathrm{mM}$ sodium phosphate buffer $\mathrm{pH} 7.0$ mounted under a $24 \times$ $50 \mathrm{~mm}^{2}$ cover slip and incubated at $80^{\circ} \mathrm{C}$ for 5 minutes. After the incubation, the slides were washed in ice-cold $70 \%$ ethanol for two minutes followed by dehydration in $70 \%, 90 \%$ and $100 \%$ ethanol respectively (2 minutes each) and air dried. Denatured probe $(100 \mu \mathrm{l})$ was then applied to the slides and covered with a $24 \times 50 \mathrm{~mm}^{2}$ cover slip. Hybridization was carried out in a moist chamber for 18 hours at $37^{\circ} \mathrm{C}$. Post-hybridization washes were performed in $2 \times$ SSC, pH 7.0 (two washes each for 5 minutes at room temperature) followed by $2 \times$ SSC for $5 \mathrm{~min}$ utes at $42^{\circ} \mathrm{C}$. Chromosomes were counter stained with DAPI $(1 \mu \mathrm{g} / \mathrm{ml})$ in Vectashield (Vector Laboratories). Fluorescence detection was done on a Zeiss Axioplan 2 Imaging microscope equipped with epifluorescence illumination and distinct filters for DAPI and FITC using 
a $100 \times$ oil immersion objective. The images were captured with a Axioplan CCD camera using Axiovision software (Zeiss, version 3.2) and processed using Adobe Photoshop 6.0 .

\section{Primers used in this study}

1. AtMND1F1 ACCGAAGAAGGGTGTAATTAGTCAGTC

\section{AtMND1R1 ATTGTCGCAGTGTGAAGATGTTATCTG}

3. MndF1 CAGGAGAATTCAAACCGAGAACATGAAACAGATCC

4. MndR1 GACGAGGATCCAATCATAGAAACAGACTTGGACC

5. Atmnd_out_FG_Rev1 CCTGGACCAGAAGAAGGTAAGGGTTTTG

6. Atmnd_out_FG_For1

GAGCTATTCACATGCTTAACAAGTTGCTAACAG

7. Nco1 F GCTCGCCCATGGCTATGTCTAAGAAACGGGGAC

8. EcoR1 R GCGGAGAATTCCTAAGCTTCATCTTGTACTAGCT

\section{LB1 AACCAGCGTGGACCGCTTGCTGCAACTC}

\section{LB2 CAGGGCCAGGCGGTGAAGG}

\section{MNDRTF1 TCGATGATGATCTTGTTGCGAA}

\section{MNDRTR1 TCACACTGATCAACAAGTTCTGCt}

\section{GAPRTR2 CAGTCTTCTGAGTAGCAGTGATTGA}

\section{GAPRTF1 AGCACGAATACAAGTCCGACCT}

\section{TSPO11R ACTGTGATAACAATGCAGCGGTTCG}

\section{TSPO11F CAGCACAATCCATTGTGGACCGTGC}

\section{Authors' contributions}

$\mathrm{AP}$ and IS conceived and designed the experiments. AP did the basic genetic and phenotypic analysis of plants together with $\mathrm{BN}, \mathrm{MM}, \mathrm{VS}$, and VV. TR characterized the Atspo11-1 mutant allele and $\mathrm{BN}$ generated the Atmnd1 Atspo11-1 double mutant. MR did the meiotic chromosome analysis. MR and AP did the FISH analysis. JS did the Real Time PCR and RNA in situ expression analysis of AtMND1. IS wrote and BN helped edit the manuscript. All coauthors reviewed and approved the final manuscript.

\section{Note added in proof}

While this manuscript was under review, a paper was published by Kerzendorfer et al., also describing work on the role of AtMND1 in homologous pairing and recombination [55].

\section{Acknowledgements}

This work was supported by the Council for Scientific and Industrial Research (CSIR), Govt. of India and by a grant from the Department of Biotechnology (DBT) to IS. AP, JS, MM, TR were supported by fellowships from CSIR, MR by a fellowship from the University Grants Commission, and $B N$ was supported by a fellowship from DBT. We acknowledge ABRC, Ohio for supply of seed material and DNA clones.

\section{References}

I. Zickler D, Kleckner N: The leptotene-zygotene transition of meiosis. Annu Rev Genet 1998, 32:619-97.

2. Bergerat A, de Massy B, Gadelle D, Varoutas PC, Nicolas A, Forterre $P$ : An atypical topoisomerase II from Archaea with implications for meiotic recombination. Nature 1997, 386:4I4-7.

3. Keeney S, Giroux CN, Kleckner N: Meiosis-specific DNA doublestrand breaks are catalyzed by Spo I I, a member of a widely conserved protein family. Cell 1997, 88:375-84.

4. Allers T, Lichten M: Differential timing and control of noncrossover and crossover recombination during meiosis. Cell 200I, 106:47-57.

5. Schwacha A, Kleckner N: Interhomolog bias during meiotic recombination: meiotic functions promote a highly differentiated interhomolog-only pathway. Cell 1997, 90:I I 23-35.

6. Hunter $\mathrm{N}, \mathrm{Kleckner} \mathrm{N}$ : The single-end invasion: an asymmetric intermediate at the double-strand break to double-holliday junction transition of meiotic recombination. Cell 200I, 106:59-70.

7. Sung P, Robberson DL: DNA strand exchange mediated by a RAD 5 I-ssDNA nucleoprotein filament with polarity opposite to that of RecA. Cell 1995, 82:453-6I.

8. Hong EL, Shinohara A, Bishop DK: Saccharomyces cerevisiae Dmcl protein promotes renaturation of single-strand DNA (ssDNA) and assimilation of ssDNA into homologous supercoiled duplex DNA. J Biol Chem 200I, 276:41 906-I2.

9. Rockmill B, Sym M, Scherthan H, Roeder GS: Roles for two RecA homologs in promoting meiotic chromosome synapsis. Genes Dev 1995, 9:2684-95.

10. Shinohara A, Gasior S, Ogawa T, Kleckner N, Bishop DK: Saccharomyces cerevisiae recA homologues RAD5I and DMCI have both distinct and overlapping roles in meiotic recombination. Genes Cells 1997, 2:615-29.

II. Dresser ME, Ewing DJ, Conrad MN, Dominguez AM, Barstead R, Jiang $\mathrm{H}$, Kodadek T: DMCI functions in a Saccharomyces cerevisiae meiotic pathway that is largely independent of the RAD5 I pathway. Genetics 1997, 147:533-44.

12. Sugawara N, Wang X, Haber JE: In vivo roles of Rad52, Rad54, and Rad55 proteins in Rad5I-mediated recombination. Mol Cell 2003, I 2:209-19.

13. Tsubouchi H, Roeder GS: The budding yeast mei5 and sae 3 proteins act together with dmcl during meiotic recombination. Genetics 2004, 168:1219-30.

14. Shinohara $A$, Ogawa $H$, Ogawa $T$ : Rad5I protein involved in repair and recombination in S. cerevisiae is a RecA-like protein. Cell 1992, 69:457-70.

15. Bishop DK, Park D, Xu L, Kleckner N: DMCI: A meiosis-specific yeast homolog of $E$. coli recA required for recombination, synaptonemal complex formation, and cell cycle progression. Cell 1992, 69:439-56.

16. Rabitsch KP, Toth A, Galova M, Schleiffer A, Schaffner G, Aigner E, Rupp C, Penkner AM, Moreno-Borchart AC, Primig M, Esposito RE, Klein $F$, Knop M, Nasmyth $K$ : A screen for genes required for meiosis and spore formation based on whole-genome expression. Curr Biol 200 I, I I:I00 I-9.

17. Gerton JL, DeRisi JL: Mnd Ip: an evolutionarily conserved protein required for meiotic recombination. Proc Natl Acad Sci USA 2002, 99:6895-900. 
18. Tsubouchi H, Roeder GS: The MndI protein forms a complex with hop2 to promote homologous chromosome pairing and meiotic double-strand break repair. Mol Cell Biol 2002, 22:3078-88.

19. Chen YK, Leng $\mathrm{CH}$, Olivares $\mathrm{H}$, Lee MH, Chang YC, Kung WM, Ti SC, Lo YH, Wang AH, Chang CS, Bishop DK, Hsueh YP, Wang TF: Heterodimeric complexes of Hop2 and MndI function with Dmcl to promote meiotic homolog juxtaposition and strand assimilation. Proc Natl Acad Sci USA 2004, I 0 I: 10572-7.

20. Leu JY, Chua PR, Roeder GS: The meiosis-specific Hop2 protein of S. cerevisiae ensures synapsis between homologous chromosomes. Cell 1998, 94:375-86.

21. Tsubouchi H, Roeder GS: The importance of genetic recombination for fidelity of chromosome pairing in meiosis. Dev Cell 2003, 5:915-25.

22. Petukhova GV, Pezza RJ, Vanevski F, Ploquin M, Masson JY, CameriniOtero RD: The Hop2 and Mnd I proteins act in concert with Rad5 I and Dmcl in meiotic recombination. Nat Struct Mol Biol 2005, I 2:449-53.

23. Enomoto R, Kinebuchi T, Sato M, Yagi $H$, Kurumizaka $H$, Yokoyama S: Stimulation of DNA strand exchange by the human TBPIP/Hop2-Mnd I complex. J Biol Chem 2006, 28I:5575-8I.

24. Pezza RJ, Petukhova GV, Ghirlando R, Camerini-Otero RD: Molecular activities of meiosis specific proteins Hop2, Mnd I and the Hop2-Mnd I complex. J Biol Chem 2006, 28 I: 18426-34.

25. Zierhut C, Berlinger M, Rupp C, Shinohara A, Klein F: MndI is required for meiotic interhomolog repair. Curr Biol 2004, 14:752-762.

26. Henry JM, Camahort R, Rice DA, Florens L, Swanson SK, Washburn MP, Gerton JL: Mnd I/Hop2 facilitates Dmcl-dependent interhomolog crossover formation in meiosis of budding yeast. Mol Cell Biol 2006, 26:2913-23.

27. Saito TT, Tougan T, Kasama T, Okuzaki D, Nojima H: Mcp7, a meiosis-specific coiled-coil protein of fission yeast, associates with Meul3 and is required for meiotic recombination. Nucleic Acids Res 2004, 32:3325-39.

28. Domenichini S, Raynaud C, Ni DA, Henry Y, Bergounioux C: Atmnd I-delta $I$ is sensitive to gamma-irradiation and defective in meiotic DNA repair. DNA Repair (Amst) 2006, 5:455-64.

29. Alonso JM, Stepanova AN, Leisse T], Kim C], Chen H, Shinn P, Stevenson DK, Zimmerman J, Barajas P, Cheuk R, Gadrinab C, Heller C, Jeske A, Koesema E, Meyers CC, Parker H, Prednis L, Ansari Y, Choy N, Deen H, Geralt M, Hazari N, Hom E, Karnes M, Mulholland C Ndubaku R, Schmidt I, Guzman P, Aguilar-Henonin L, Schmid M, Weigel D, Carter DE, Marchand T, Risseeuw E, Brogden D, Zeko A Crosby WL, Berry CC, Ecker JR: Genome-wide insertional mutagenesis of Arabidopsis thaliana. Science 2003, 301:653-657.

30. McElroy D, Chamberlain DA, Moon E, Wilson KJ: Development of gusA reporter gene constructs for cereal transformation: Availability of plant transformation vectors from the CAM BIA Molecular Genetic Resource Service. Mol Breeding 1995 I:27-37.

31. Alexander MP: Differential staining of aborted and nonaborted pollen. Stain Technol 1969, 44: I 17-22.

32. Sanders PM, Bui AQ, Weterings K, McIntire KN, Hsu YC, Lee PY, Truong MT, Beals TP, Goldberg RB: Anther developmental defects in Arabidopsis thaliana male-sterile mutants. Sex Plant Reprod 1999, I I:297-322.

33. Ross KJ, Fransz P, Armstrong SJ, Vizir I, Mulligan B, Franklin FC, Jones $\mathrm{GH}$ : Cytological characterization of four meiotic mutants of Arabidopsis isolated from T-DNA-transformed lines. Chromosome Res 1997, 5:55I-559.

34. Ross KJ, Fransz P, Jones GH: A light microscopic atlas of meiosis in Arabidopsis thaliana. Chromosome Res 1996, 4:507-16.

35. Li W, Yang X, Lin Z, Timofejeva L, Xiao R, Makaroff CA, Ma H: The AtRAD5IC gene is required for normal meiotic chromosome synapsis and double-strand break repair in Arabidopsis. Plant Physiol 2005, I38:965-76.

36. Grelon M, Vezon D, Gendrot G, Pelletier G: AtSPOI I-I is necessary for efficient meiotic recombination in plants. $E M B O$ 200I, 20:589-600

37. Yin $Y$, Cheong $\mathrm{H}$, Friedrichsen $D$, Zhao $Y, H u J$, Mora-Garcia S, Chory J: A crucial role for the putative Arabidopsis topoisomeras V in plant growth and development. Proc Natl Acad Sci USA 2002, 99:10191-10196.
38. Schommer C, Beven A, Lawrenson T, Shaw P, Sablowski R: AHP2 is required for bivalent formation and for segregation of homologous chromosomes in Arabidopsis meiosis. Plant J 2003, 36: I-II.

39. Caryl AP, Jones GH, Franklin FC: Dissecting plant meiosis using Arabidopsis thaliana mutants. J Exp Bot 2003, 54:25-38.

40. Li W, Ma H: Double-stranded DNA breaks and gene functions in recombination and meiosis. Cell Res 2006, 16:402-12.

41. Couteau F, Belzile F, Horlow C, Grandjean O, Vezon D, Doutriaux MP: Random chromosome segregation without meiotic arrest in both male and female meiocytes of a dmcl mutant of Arabidopsis. Plant Cell 1999, II:1623-1634.

42. Puchta $\mathrm{H}$ : The repair of double-strand breaks in plants: mechanisms and consequences for genome evolution. J Exp Bot 2005, 56: I-I4.

43. Ramesh MA, Malik SB, Logsdon JM Jr: A phylogenomic inventory of meiotic genes; evidence for sex in Giardia and an early eukaryotic origin of meiosis. Curr Biol 2005, 15: I85-9|.

44. Reddy TV, Kaur J, Agashe B, Sundaresan V, Siddiqi I: The DUET gene is necessary for chromosome organization and progression during male meiosis in Arabidopsis and encodes a PHD finger protein. Development 2003, 130:5975-87.

45. Canales C, Bhatt AM, Scott R, Dickinson $H$ : EXS, a putative LRR receptor kinase, regulates male germline cell number and tapetal identity and promotes seed development in Arabidopsis. Curr Biol 2002, 12:17|8-27.

46. Zhao DZ, Wang GF, Speal B, Ma H: The EXCESS MICROSPOROCYTESI gene encodes a putative leucine-rich repeat receptor protein kinase that controls somatic and reproductive cell fates in the Arabidopsis anther. Genes Dev 2002, |6:202I-3|.

47. Yang SL, Xie LF, Mao HZ, Puah CS, Yang WC, Jiang L, Sundaresan V, Ye D: TAPETUM DETERMINANTI is required for cell specialization in the Arabidopsis anther. Plant Cell 2003, 15:2792-804.

48. Siddiqi I, Ganesh G, Grossniklaus U, Subbiah V: The dyad gene is required for progression through female meiosis in Arabidopsis. Development 2000, 127:197-207.

49. Dellaporta SL, Wood J, Hicks JB: A plant DNA minipreparation: version II. Plant Mol Bio Rep 1983, I: | 9-21.

50. Bechtold N, Pelletier G: In planta Agrobacterium-mediated transformation of adult Arabidopsis thaliana plants by vacuum infiltration. Methods Mol Biol 1998, 82:259-66.

51. Smyth DR, Bowman JL, Meyerowitz EM: Early flower development in Arabidopsis. Plant Cell 1990, 2:755-67.

52. Agashe B, Prasad CK, Siddiqi I: Identification and analysis of DYAD: a gene required for meiotic chromosome organisation and female meiotic progression in Arabidopsis. Development 2002, 129:3935-43.

53. Fransz P, Armstrong S, Alonso-Blanco C, Fischer TC, Torres-Ruiz RA, Jones G: Cytogenetics for the model system Arabidopsis thaliana. Plant J 1998, 13:867-76.

54. Schneitz K, Hulskamp M, Pruitt RE: Wild-type ovule development in Arabidopsis thaliana: a light microscope study of cleared whole-mount tissue. Plant J 1995, 7:731-749.

55. Kerzendorfer C, Vignard J, Pedrosa-Harand A, Siwiec T, Akimcheva S, Jolivet S, Sablowski R, Armstrong S, Schweizer D, Mercier R, Schlogelhofer P: The Arabidopsis thaliana MNDI homologue plays a key role in meiotic homologous pairing, synapsis and recombination. J Cell Sci 2006, I I 9:2486-96. 